\title{
DETERMINAÇÃO DA PRODUÇÃO DE BIOGÁS EM UMA FÁBRICA DE CHOCOLATES PARA FINS DE APROVEITAMENTO ENERGÉTICO
}

\author{
DETERMINATION OF BIOGAS PRODUCTION IN A CHOCOLATE FACTORY FOR \\ ENERGY USE PURPOSES
}

\author{
Flávio Raposo Pereira a , Julio Pansiere Zavarise a, Laura Marina Pinotti a \\ aUniversidade Federal do Espirito Santo (UFES) \\ raposocst@hotmail.com, juliopz2011@gmail.com,pinotti2008@hotmail.com \\ Submissão: 13 de março de 2021 Aceitação: 28 de julho de 2021
}

\section{Resumo}

Os efluentes líquidos das fábricas de chocolates demandam tratamento, dado o seu potencial poluidor. Uma alternativa é empregar o tratamento anaeróbio, que remove parcialmente a matéria orgânica e produz biogás. A produção de biogás pode ser estimada por meio de equações matemáticas simples, e a partir dessas estimativas pode ser avaliado o uso energético desse insumo. O objetivo deste trabalho foi estimar o biogás produzido em um Reator Anaeróbio de Fluxo Ascendente (UASB, sigla em inglês) na unidade de tratamento de efluentes industriais e sanitários de uma fábrica de chocolates e avaliar dois cenários hipotéticos de aproveitamento energético do biogás gerado. O método usado para a estimativa da produção de metano foi - AMS III.H, com adaptações. Após a análise estatística, os dados amostrais indicaram que foram gerados cerca de $49020 \mathrm{Nm}^{3} /$ ano de biogás, com uma taxa de produção igual a 0,21 $\mathrm{Nm}^{3}$ biogás/kg de Demanda Química de Oxigênio (DQO) removida. O trabalho concluiu que o cenário de aproveitamento energético do biogás para a geração de vapor em caldeiras apresentou-se superior pelo seu baixo custo relativo de manutenção, pela pronta adaptabilidade dos sistemas de gás natural para biogás e pelas vantagens ambientais oferecidas.

Palavras-Chave: Chocolates e Derivados; Equações Matemáticas Simples; Remoção de DQO; Tratamento Anaeróbio

\section{Abstract}

Liquid effluents from chocolate factories require treatment, given their polluting potential. An alternative is to employ anaerobic treatment, which partially removes organic matter and produces biogas. Is possible to estimate the production of biogas by simple mathematical equations and from these estimates the energetic use can be evaluated. The objective of this work was to estimate the biogas produced in an Upflow Anaerobic Reactor (UASB) in the industrial and sanitary effluent treatment unit of a chocolate factory and to evaluate two hypothetical scenarios for the energy use of the generated biogas. The method used to estimate methane production was AMS III.H, with adaptations. After statistical analysis, sample data indicated a generation of $49020 \mathrm{Nm}^{3} / \mathrm{year}$ of biogas, with a production rate equal to $0.21 \mathrm{Nm} 3$ biogas $/ \mathrm{kg}$ of Chemical Oxygen Demand (COD) removed. The work concluded that the scenario of biogas energy use for steam generation in boilers was superior due to its relatively low maintenance cost, the ready adaptability of natural gas systems for biogas and the environmental advantages offered.

Keywords: Chocolates and Derivatives; Simple Mathematical Equations; COD removal; Anaerobic treatment. 


\section{INTRODUÇÃO}

As fábricas de chocolates e derivados não diferem das demais fábricas quanto à necessidade de implementar processos mais sustentáveis, pois geram efluentes líquidos poluentes que não devem ser descartados sem o devido tratamento. Ainda é preciso ressaltar que a produção e o consumo de produtos de confeitaria (como chocolates, biscoitos e doces) aumentam em todo o mundo (DERELI, 2019).

O chocolate é definido como um sistema multifásico complexo de particulados (açúcar, cacau e leite) e fases contínuas (manteiga de cacau, gordura do leite e emulsificantes) (ELKALYOUBI et al., 2011). Uma grande quantidade de água é usada nos processos da produção industrial de chocolates, especialmente nas etapas de pulverização e mistura (PATIL et al., 2009). Sendo assim, as águas residuárias de sua fabricação podem conter elevadas concentrações de lipídios e carboidratos. Além disso, a variabilidade diária e sazonal em sua composição e quantidade (RICHTER; LANNES, 2007) é algo que afeta negativamente 0 processo de descarte (ZAJDA; ALEKSANDER-KWATERCZAK, 2019).

Em geral, os efluentes das fábricas de chocolates e derivados contêm altas concentrações de matéria orgânica facilmente biodegradável, com o teor de Demanda Química de Oxigênio (DQO) variando entre 2500 e $5400 \mathrm{mg} / \mathrm{L}$ e Demanda Bioquímica de Oxigênio (DBO) entre 1840 e 4910 mg/L (BEAL; RAMAN, 2000; DIWANI et al., 2000; ERSAHIN et al., 2011). Estes efluentes não contêm ingredientes tóxicos, mas possuem alto teor de sólidos totais (ST), além dos valores elevados de DQO e DBO (COPETTI et al., 2013), já mencionados anteriormente, que podem ser tratados por sistemas de lodos ativados convencionais (MASSARA et al., 2017).

O estudo de van Lier e colaboradores (2015) destacou que com o uso do tratamento anaeróbio em vez de lodos ativados cerca de até $1 \mathrm{kWh}$ de energia fóssil por quilograma de DQO removida é economizado, dependendo do sistema que é usado para aeração dos lodos ativados. Além disso, sob condições anaeróbias a matéria orgânica é convertida em metano, produzindo cerca de 13,5 MJ de energia útil por quilograma de DQO removida. Em contrapartida, o funcionamento do processo anaeróbio é sensível a mudanças repentinas na composição e/ou volume do efluente tratado. Isso pode ser listado como uma desvantagem deste último frente ao tratamento aeróbio (CHERNICHARO et al., 2015).

A tecnologia anaeróbia para o tratamento de efluentes industriais melhorou significativamente nas últimas quatro décadas com a aplicações de reatores configurados de diferentes formas (LIER et al., 2015). Como destaque, podem ser citados os reatores anaeróbios de alta taxa, que atuam com tempos de retenção hidráulica reduzidos em comparação aos reatores convencionais (MAINARDI; BUTTAZZONI; GOI, 2020). Dentre aqueles, o Reator Anaeróbio de Fluxo Ascendente (UASB, sigla em inglês) apresenta simplicidade operacional, baixo consumo de energia e baixa exigência relativa de espaço (ESPARZA-SOTO et al., 2013). Outras vantagens incluem a possibilidade de recuperação energética por meio do biogás e a operação em ambiente mesofílico (MASSARA et al., 2017).

O estudo conduzido por Alcaraz-lbarra e colaboradores (2020) avaliou o desempenho de um reator UASB na remoção de matéria orgânica em efluentes líquidos de uma fábrica de chocolates em Toluca (México), sob condições de baixa temperatura (entre 17 e $19^{\circ} \mathrm{C}$ ). As águas residuárias brutas tinham a média de DQO total igual a $7372 \mathrm{mg} / \mathrm{L}$ e $\mathrm{pH}$ baixo $(4,3)$. O processo de tratamento anaeróbio foi conduzido em escala piloto com um reator de $244 \mathrm{~L}$, durante 275 dias. Como resultados, obteve-se uma remoção de DQO entre 39 e $84 \%$ e uma produção de biogás que variou entre 119 e $834 \mathrm{~L} / \mathrm{dia}$, com um teor de metano $(\mathrm{CH} 4)$ de $84 \%$.

É digno de nota que a maioria dos esforços em pesquisas acerca do tratamento anaeróbio de efluentes industriais são voltados para uma maior produtividade de biogás (ZHANG; HU; LEE, 2016). O biogás gerado nos reatores UASB por meio da digestão anaeróbia de efluentes industriais é geralmente constituído por um alto teor de metano, comumente superior a $60 \%$, e gás carbônico (CO2) em menor quantidade. O metano é um gás de efeito estufa e pode ser utilizado no suprimento energético das fábricas (aquecimento e eletricidade) em vez de ser emitido para a atmosfera (EL-FADEL; MASSOUD, 2001).

A fim de estimar a produção de biogás no 
tratamento anaeróbio de efluentes, vários métodos já foram desenvolvidos. Esses métodos foram elaborados em função do tipo de tratamento e suas características, abrangendo unidades de tratamento de esgotos domésticos e industriais, de resíduos sólidos urbanos e aterros sanitários (CHERNICHARO, 2007; SHOW; LEE, 2008; GERVASONI; CANTÃO, 2011). Nesse nicho de pesquisa houve avanços significativos com 0 desenvolvimento e aprimoramento de modelos capazes de realizar o inventário completo das emissões de biogás e ainda avaliar o seu potencial de recuperação energética em ambientes industriais (ANTWI et al., 2017; PIN et al., 2020).

Considerando a importância das estimativas teóricas da produção de biogás para propor estratégias adequadas de recuperação energética dos efluentes líquidos gerados no processamento industrial de alimentos, o objetivo deste trabalho foi estimar a produção de biogás a partir do tratamento anaeróbio em um reator UASB dos efluentes líquidos gerados em uma fábrica de chocolates e avaliar a viabilidade técnica e econômica de dois diferentes cenários de aproveitamento energético do biogás produzido.

\section{METODOLOGIA}

A presente pesquisa foi realizada em uma fábrica de chocolates e derivados localizada no Estado do Espírito Santo, que utilizava um reator UASB para tratar todos os seus efluentes industriais e sanitários. Os parâmetros investigados foram: DQO, DBO e a vazão dos efluentes durante um período de 18 meses. Esses parâmetros foram analisados e monitorados para determinar a eficiência do tratamento e, por conseguinte, garantir os níveis legais de matéria orgânica nos efluentes.

As análises físico-químicas foram realizadas pela equipe técnica da fábrica. Os métodos utilizados se encontram descritos em documentos internos da fábrica, que detalham os parâmetros, a frequência de amostragem, os pontos de coleta e procedimentos. Esses documentos foram elaborados com base na norma Standard Methods for Examination of Water and Wastewater 19a ed., da American Public Health Association (APHA) (APHA, 1995).

O tratamento estatístico dos dados foi realizado com o auxílio do software Minitab 19.0, com o objetivo de verificar a variabilidade das análises de DQO, da remoção de DQO e das medidas de vazão dos efluentes. Para isso, foi aplicado um teste de normalidade de AndersonDarling, com nível de significância igual a 5\%.

O método utilizado para a estimativa da produção de metano foi estabelecido pela Convenção-Quadro das Nações Unidas sobre a Mudança do Clima (UNFCCC, sigla em inglês), e é referido como o método AMS III.H. Para estimar somente a produção de metano (em toneladas anuais de $\mathrm{CH}_{4}$ emitido), desconsiderou-se $\mathrm{o}$ potencial de aquecimento global desse gás (GWP $\mathrm{CH}_{4}$, sigla em inglês), conforme apresentado na eq. 1 (SHOW; LEE, 2008; GERVASONI; CANTÃO, 2011; UNFCCC, 2012).

$P_{C H 4}=Q * S_{0} * \eta_{\text {rem }} * \mathrm{FP}_{\mathrm{CH} 4} * \mathrm{FCM} * \mathrm{FCI}$

Onde:

$\mathrm{P}_{\mathrm{CH} 4}=$ Produção de metano de uma estação de tratamento de efluentes (toneladas/ano), $\mathrm{Q}=$ Volume de efluentes tratados ( $\mathrm{m}^{3} / \mathrm{ano}$ ), $\mathrm{S}_{0}=$ Concentração da $\mathrm{DQO}$ dos efluentes (toneladas $/ \mathrm{m}^{3}$ ),

$\eta_{\text {rem }}=$ Eficiência de remoção da DQO dos efluentes, $\mathrm{FP}_{\mathrm{CH} 4}=$ Fator de produção do metano,

FCM = Fator de correção do metano em função do tipo de tratamento e

$\mathrm{FCl}=$ Fator de correção devido às incertezas.

Os valores do fator de produção de metano $\left(\mathrm{FP}_{\mathrm{CH} 4}\right)$ e do fator de correção devido às incertezas ( $\mathrm{FCl})$ foram obtidos no guia para inventários de gases de efeito estufa do Painel Intergovernamental sobre Mudanças Climáticas (IPCC, sigla em inglês). O fator de produção do metano foi considerado como sendo igual a 0,25 tonelada de $\mathrm{CH}_{4}$ por tonelada de DQO removida e o fator de correção devido às incertezas igual a 0,89 (IPCC, 2006). Já o fator de correção (FCM) variou de 0 a 1 , de acordo com a via de tratamento e/ou destinação. Para reatores UASB com recuperação do $\mathrm{CH}_{4}$, esse valor é igual a 0,8 (IPCC, 2006).

Para calcular a eficiência do sistema de tratamento foi considerada a remoção da carga orgânica, especificamente a remoção de DQO, conforme a eq. 2 (COMPANHIA AMBIENTAL DO ESTADO DE SÃO PAULO - CETESB, 2006). 


$$
\eta_{\text {rem }}(\%)=\frac{\mathrm{DQO}_{\text {Afluente }}-\mathrm{DQO}_{\text {Efluente }}}{D Q O_{\text {Afluente }}} \times 100
$$

Onde:

$\eta_{\text {rem }}=$ Eficiência de remoção da DQO (\%), $\mathrm{DQO}_{\text {Afluente }}=\mathrm{DQO}$ afluente ao reator $(\mathrm{mg} / \mathrm{L}) \mathrm{e}$ $D Q O_{\text {Efluente }}=\mathrm{DQO}$ efluente ao reator $(\mathrm{mg} / \mathrm{L})$.

A produção total de biogás foi calculada a partir da produção e da concentração esperada de metano, de acordo com a eq. 3 . Foi considerada a concentração de $70 \%$ de metano, já que o biogás de reatores UASB é geralmente constituído por um alto teor desse gás, situado entre 65 e 70\% (PILARSKA, 2018; PILARSKA et al., 2019).

$$
P_{\text {Biogás }}=\frac{P_{C H 4}}{C_{C H 4}}
$$

Onde:

$P_{\text {Biogás }}=$ Produção de biogás $\left(\mathrm{Nm}^{3} / \mathrm{ano}\right)$,

$P_{C H 4}=$ Produção de metano da estação de tratamento de efluentes ( $\left.\mathrm{Nm}^{3} / \mathrm{ano}\right) \mathrm{e}$

$\mathrm{C}_{\mathrm{CH} 4}=$ Concentração de metano (\%).

Foram propostos dois cenários para 0 aproveitamento do biogás, sendo o primeiro voltado para a geração própria de eletricidade e o segundo para a geração de vapor em caldeiras. Esses cenários foram elaborados em função da possibilidade de conversão energética do biogás em eletricidade na própria fábrica, utilizando-se um grupo motor gerador ou realizando-se a queima direta do biogás nas duas caldeiras a gás natural (GN) já existentes no local. Para a obtenção dos custos dos investimentos iniciais foram coletadas informações na literatura e com fornecedores, a fim de se realizar o levantamento e orçamento dos materiais, equipamentos, as especificações, quantidades e os custos de manutenção.

A receita do cenário de geração de eletricidade foi obtida pela aplicação simultânea da eq. 4 e da eq. 5. Para isso, foi considerada a tarifa de eletricidade homologada pela Agência Nacional de Energia Elétrica (ANEEL), para a concessionária EDP-ECELSA e para a faixa e modalidade de consumo da fábrica estudada no período de 01/01/2021 a 31/05/2021.

$$
\mathrm{R}_{\mathrm{E}}=\mathrm{N} * \mathrm{H} * \mathrm{~T} * \mathrm{P}
$$

$$
\mathrm{P}=P_{\text {Biogás }} * P C I_{\text {Biogás }} * \frac{\mathrm{E}}{\mathrm{K}}
$$

Onde:

$R_{E}=$ Receita pela geração de eletricidade ( $\left.R \$ / a n o\right)$, $\mathrm{N}$ = Número de dias de operação do motor gerador (364 dias/ano),

$\mathrm{H}=$ Horas de trabalho do motor gerador $(20 \mathrm{~h} / \mathrm{dia})$, $\mathrm{T}=$ Tarifa de eletricidade da concessionária $(\mathrm{R} \$ / \mathrm{kWh})$,

$\mathrm{P}=$ Potência disponível do biogás $(\mathrm{kW})$,

$\mathrm{PCl}_{\text {Biogás }}=$ Poder Calorífico Inferior estimado do biogás com $70 \%$ de $\mathrm{CH}_{4}\left(5500 \mathrm{kcal} / \mathrm{Nm}^{3}\right)$ (FELCA et al., 2015), $E$ = Eficiência de conversão global do grupo motor gerador (17,4\%) (LEMOS, 2013) e $\mathrm{K}=$ constante para ajuste das unidades $(31,54$ * 109) (PEREIRA et al., 2020).

A receita do cenário para a queima direta do biogás em caldeiras provém da redução da despesa obtida pela substituição parcial do GN. A receita foi calculada por meio da eq. 6, considerando-se a tarifa de GN obtida na Agência de Regulação de Serviços Públicos do Estado do Espírito Santo (ARSP-ES) no dia 01/05/2021.

$\mathrm{R}_{\mathrm{B}}=P_{\text {Biogás }}{ }^{*} \mathrm{~F}^{*} \mathrm{~T}_{\mathrm{GN}}$

Onde:

$R_{B}=$ Receita gerada pela substituição do $G N(R \$)$, $\mathrm{F}=$ Fator de conversão $\left(0,58 \mathrm{Nm}^{3} \mathrm{GN} / \mathrm{Nm}^{3}\right.$ biogás $)$ (IPCC, 2006) e

$T_{G N}=$ Tarifa do $G N$ da concessionária $\left(R \$ / \mathrm{Nm}^{3}\right)$ (ARSP-ES, 2021).

Os benefícios anuais para os cenários avaliados foram obtidos a partir do cálculo da diferença entre a receita anual gerada e os custos totais envolvidos, que incluem os custos de instalação e de manutenções dos sistemas de aproveitamento energético do biogás. A taxa de desconto (TD) escolhida foi de $3,50 \%$ a.a., baseada no Sistema Especial de Liquidação e de Custódia (SELIC), vigente a partir de 06/05/2021 (BANCO CENTRAL DO BRASIL-BCB, 2021). A TD foi utilizada para determinar o tempo de retorno do investimento inicial ou payback descontado. O payback descontado foi calculado como sendo o tempo decorrido entre o investimento inicial e o momento em que a diferença acumulada entre as receitas anuais e os custos de manutenção são 
iguais ao valor do investimento despendido (CAMPELLO et al., 2021).

Para avaliar a viabilidade econômica dos investimentos foram calculados o Valor Presente Líquido (VPL) e a Taxa Interna de Retorno (TIR), conforme metodologia descrita por Avaci e colaboradores (2013). O VPL representa, em valores monetários atuais, a diferença entre os recebimentos e os pagamentos de todo o projeto. Se o VPL for positivo, significa que foi recuperado o investimento inicial aplicado à TD (CERVI; ESPERANCINI; BUENO, 2010). O método da TIR requer o cálculo da taxa que zera o VPL. Se a TIR $>$ TD, o investimento é considerado atrativo economicamente, e se TIR < TD, o investimento é tido como não atrativo (CAMPELLO et al., 2021).

\section{RESULTADOS E DISCUSSÃO}

Verificou-se a eficiência de remoção da DQO no reator UASB e a variabilidade das medidas de vazão e das análises de DQO dos efluentes para um período de 18 meses. Na Tabela 1, são apresentadas as médias mensais dos dados coletados de cada parâmetro (DBO e DQO) das correntes relacionadas ao reator UASB em estudo, tanto da corrente afluente quanto da efluente.

Na Figura 1 são mostrados os diagramas de caixas (boxplots) dos dados de DQO afluente (letra a), de vazão (letra b) e eficiência de remoção de DQO (letra c).

Todas as amostras analisadas estavam de acordo com o teste de normalidade de AndersonDarling, com p-valor de 0,330 para os dados de DQO da corrente afluente, $p$-valor de 0,396 para as medidas de vazão e p-valor de 0,077 para as medidas de eficiência de remoção de DQO. A média aritmética da concentração de DQO a montante do reator foi igual a $3054 \mathrm{mg} / \mathrm{L}$, enquanto a média aritmética das medidas de vazão foi de $205,2 \mathrm{~m}^{3} /$ dia, como mostrado na letra $b$ da Figura 1. Os desvios padrões para as medidas de DQO e para as medidas de vazão foram iguais a $644 \mathrm{mg} / \mathrm{L}$ e $22,3 \mathrm{~m}^{3} /$ dia, respectivamente.

Figura 1 - Boxplots dos dados operacionais da fábrica de chocolates em estudo
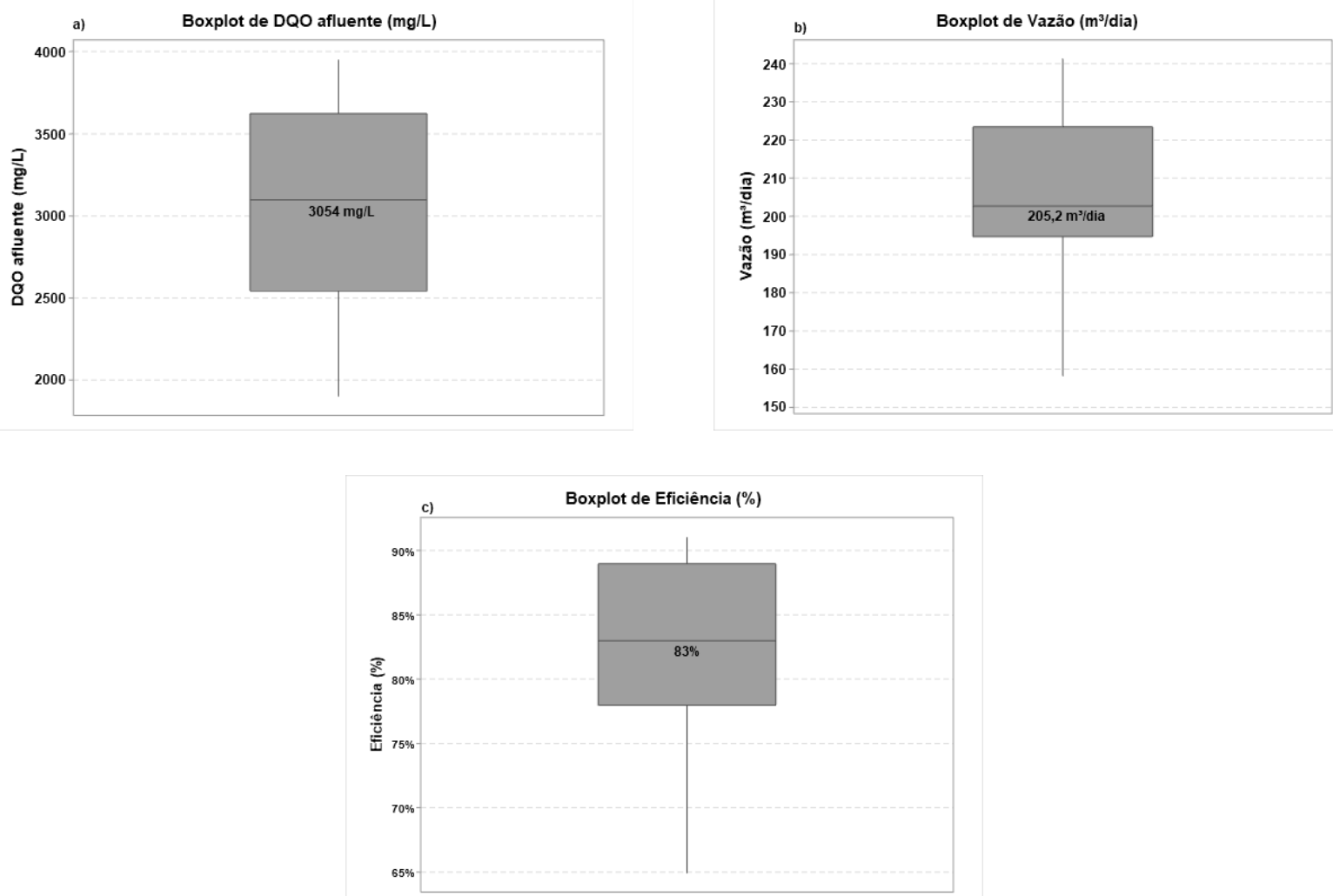

Fonte: Elaboração própria (2021). 
Observou-se ainda, na letra c da Figura 1, que as medidas mensais de eficiências de remoção se concentraram acima de $75 \%$ e que a média aritmética de eficiência de remoção de DQO variou em torno de $83 \%$. As medidas de eficiência de remoção de DQO apresentaram uma baixa variabilidade, com desvio padrão igual a $6 \%$, indicando a estabilidade do sistema de tratamento anaeróbico para os efluentes avaliados.

Ozgun e colaboradores (2012) estudaram uma fábrica de confeitos na Turquia que gera cerca de $170.000 \mathrm{~m}^{3}$ de águas residuárias por ano, que são caracterizadas por altas concentrações de poluentes orgânicos solúveis e $\mathrm{pH}$ baixo. $\mathrm{O}$ tratamento com $\mathrm{o}$ Reator Anaeróbio de Manta de Lodo Granular Expandida (EGSB, sigla em inglês) levou a uma remoção de DQO máxima de $88 \%$. Mesmo que o trabalho supracitado tenha aplicado um reator do tipo EGSB, nota-se que a remoção máxima de DQO obtida é bastante semelhante à máxima eficiência de remoção encontrada neste trabalho (91\%), que pode ser vista na Tabela 1. Por mais que haja significativa diferença nas configurações dos reatores anaeróbios empregados, acredita-se que existem indícios de efetividade do tratamento anaeróbio em RAAT para os efluentes das fábricas de confeitos, quando se considera a elevada eficiência de remoção de DQO.

As principais características relativas ao processo de tratamento dos efluentes da fábrica de chocolates e derivados em estudo podem ser observadas na Tabela 2.

Tabela 1 - Dados obtidos do reator UASB da fábrica de chocolates estudada para um período de 18 meses de coleta de dados operacionais

\begin{tabular}{|c|c|c|c|c|c|c|}
\hline \multirow[b]{2}{*}{ Mês } & \multicolumn{2}{|c|}{ Afluente ao reator } & \multicolumn{2}{|c|}{ Efluente do reator } & \multirow{2}{*}{$\begin{array}{l}\text { Média } \\
\text { de Vazão } \\
\left.\text { ( } \mathbf{m}^{3} / \text { dia }\right)\end{array}$} & \multirow{2}{*}{$\begin{array}{l}\text { Eficiência } \\
\text { de remoção } \\
\text { de DQO (\%) }\end{array}$} \\
\hline & $\begin{array}{l}\text { DQO } \\
\text { (mg/L) }\end{array}$ & $\begin{array}{c}\text { DBO } \\
(\mathrm{mg} / \mathrm{L})\end{array}$ & $\begin{array}{c}\text { DQO } \\
\text { (mg/L) }\end{array}$ & $\begin{array}{l}\text { DBO } \\
\text { (mg/L) }\end{array}$ & & \\
\hline 1 & 3624,6 & 2077,9 & 413,0 & 320,8 & 207,1 & $89 \%$ \\
\hline 2 & 3866,5 & 2090,0 & 380,0 & 369,4 & 233,3 & $90 \%$ \\
\hline 3 & 3780,0 & * & 378,0 & * & 182,2 & $90 \%$ \\
\hline 4 & 3698,0 & * & 389,0 & * & 201,5 & $89 \%$ \\
\hline 5 & 3605,0 & 2180,0 & 397,3 & 265,3 & 204,0 & $89 \%$ \\
\hline 6 & 2352,5 & 1526,9 & 441,2 & 184,0 & 199,6 & $81 \%$ \\
\hline 7 & 2545,0 & 1469,3 & 601,0 & 144,1 & 196,3 & $76 \%$ \\
\hline 8 & 3109,5 & 1391,3 & 496,8 & 221,7 & 201,3 & $84 \%$ \\
\hline 9 & 3010,0 & 1847,2 & 674,0 & 262,5 & 205,2 & $78 \%$ \\
\hline 10 & 2221,0 & 993,1 & 540,0 & 232,5 & 210,2 & $76 \%$ \\
\hline 11 & 2097,1 & 816,5 & 238,0 & 141,8 & 220,6 & $89 \%$ \\
\hline 12 & 2547,5 & 1420,1 & 240,7 & 256,8 & 232,2 & $91 \%$ \\
\hline 13 & 3058,0 & 1819,4 & 662,6 & 250,3 & 241,2 & $78 \%$ \\
\hline 14 & 3291,9 & 1706,8 & 571,0 & 272,9 & 240,0 & $83 \%$ \\
\hline 15 & 1908,2 & 1079,3 & 670,6 & 278,0 & 195,8 & $65 \%$ \\
\hline 16 & 3948,7 & 2006,3 & 676,0 & 296,3 & 173,1 & $83 \%$ \\
\hline 17 & 3209,4 & 1691,4 & 679,6 & 203,3 & 158,3 & $79 \%$ \\
\hline 18 & 3100,0 & 1878,5 & 655,0 & 312,8 & 191,6 & $79 \%$ \\
\hline
\end{tabular}

$\left(^{*}\right)$ Análises não realizadas. Fonte: Elaboração própria (2021).

Embora, haja indícios acerca da efetividade do tratamento anaeróbio, haja vista a média de remoção de DQO obtida neste trabalho (83\%) quando comparada ao trabalho de Alcaraz-lbarra e colaboradores (2020), que encontraram uma média de eficiência de remoção de DQO igual a 59,5\%, é preciso pontuar que existem alguns pontos negativos relacionados à operação do reator UASB. 
Um desses pontos negativos é a sensibilidade a variações extremas do fluxo de afluentes, que pode ser influenciado pelas chuvas sazonais ou pela produção aumentada em algumas épocas do ano. Essas variações podem afetar negativamente 0 desempenho dos sistemas de remoção de carga orgânica via reator UASB (CHERNICHARO et al., 2015).

Apesar de, na literatura, constar um fator de emissão de $7,12 \mathrm{~kg}$ de DBO por tonelada de produtos em fábricas de chocolates e doces diversos (CETESB, 2006), os resultados desta pesquisa encontraram um fator de $1,01 \mathrm{~kg}$ de $\mathrm{DBO} / \mathrm{t}$, que foi apresentado na Tabela 2. Alguns processos industriais específicos podem alterar significativamente a carga orgânica dos efluentes industriais. A esses processos, somam-se algumas tecnologias capazes de otimizar a produção, as quais podem reduzir a níveis mínimos a perda de matéria-prima nos efluentes. Isso implica que comparações diretas entre os fatores de emissão de DBO ou DQO obtidos para diferentes fábricas não podem ser realizadas, uma vez que não é possível dispor de informações detalhadas acerca das tecnologias e dos processos industriais utilizados na linha de produção, pois estes são protegidos por segredo industrial.

Tabela 2 - Características dos efluentes da fábrica de chocolate e derivados em estudo para o período de acompanhamento dos dados operacionais

\begin{tabular}{llc}
\hline Parâmetros & Unidade & Resultados \\
\cline { 3 - 3 } & & Média \\
\hline Vazão & $\mathrm{M} / \mathrm{dia}$ & 205,2 \\
DQO afluente ao reator & $\mathrm{mg} / \mathrm{L}$ & 3054 \\
DQO efluente ao reator & $\mathrm{mg} / \mathrm{L}$ & 505,8 \\
Eficiência de remoção de DQO & $\%$ & 83 \\
DBO afluente ao reator & $\mathrm{mg} / \mathrm{L}$ & 1624 \\
DBO efluente ao reator & $\mathrm{mg} / \mathrm{L}$ & 250,8 \\
Produção de chocolates & $\mathrm{t} / \mathrm{mês}$ & 9869 \\
Fator de emissão DBO & $\mathrm{kg}$ de DBO/t & 1,01 \\
Fator de emissão DQO & $\mathrm{kg}$ de DQO/t & 1,90 \\
\hline
\end{tabular}

Fonte: Elaboração própria (2021).

Na Tabela 3 é apresentado o memorial de cálculos que foi utilizado para estimar a produção de biogás no período em que os dados operacionais foram coletados

Observa-se na Tabela 3 que foi estimada uma produção anual de biogás igual a $49.020 \mathrm{Nm}^{3} /$ ano e uma taxa líquida de emissão, igualmente estimada, de $0,21 \mathrm{Nm}^{3}$ de biogás por quilograma de DQO removida, já incluídas as perdas estimadas do metano carreado nos efluentes e no lodo. A taxa bruta de emissão de biogás estimada foi igual a 0,32 $\mathrm{Nm}^{3}$ de biogás por quilograma de DQO removida e foi obtida quando se considerou a estimativa de produção total desse gás nos cálculos realizados.

$O$ tratamento de efluentes de padarias em reator UASB foi investigado por Mohan, Vivekanandhan e Priyadharshini (2017). Segundo esses autores, o efluente de padarias, assim como o efluente da indústria de chocolates, tem um elevado teor de sólidos altamente biodegradáveis e valores expressivos de DQO (entre 5500 e $7000 \mathrm{mg} / \mathrm{L}$ ), o que o torna apto para o tratamento pela via anaeróbia (MOHAN; VIVEKANANDHAN; PRIYADHARSHINI, 2017). A remoção máxima de DQO encontrada foi igual a $83,10 \%$ e a produção de biogás alcançada variou entre 0,27 e 0,32 $\mathrm{Nm}^{3} / \mathrm{kg}$ de DQO removida.

Saner, Mungray e Mistry (2016) estudaram a aplicação de um reator UASB no tratamento de efluentes líquidos de alta resistência de uma destilaria e alcançaram uma remoção máxima de DQO igual a $68,35 \%$ e uma produção média de biogás igual a $0,38 \mathrm{Nm}^{3} / \mathrm{kg}$ de DQO removida. $\mathrm{O}$ trabalho de Chen e colaboradores (2019) avaliou o 
tratamento anaeróbio de efluentes líquidos e sólidos do processamento de café, caracterizados por um elevado teor de ST e de matéria orgânica, em um reator anaeróbio de membrana, e obtiveram uma eficiência de remoção máxima igual a $92 \%$ e uma produção média de biogás igual a $0,28 \mathrm{Nm}^{3} / \mathrm{kg}$ de DQO removida. Segundo Astals e colaboradores (2011), a produção de biogás em função da remoção de DQO pode atingir valores entre 0,28 e $0,58 \mathrm{Nm}^{3}$ por quilograma de DQO removida, o que vem ao encontro dos resultados obtidos neste trabalho assim como dos demais citados anteriormente. É notável que em todos os trabalhos avaliados a produção média de biogás em função da remoção de DQO dos efluentes da produção industrial de alimentos (pães, café e bebidas destiladas) é consideravelmente semelhante àquela encontrada neste estudo, mesmo considerando-se as diferenças existentes (tipo de reator e composição dos efluentes tratados).

Tabela 3 - Memorial de cálculos para a estimativa de produção de biogás

\begin{tabular}{|c|c|c|c|}
\hline Descrição / Unidades & Etapa & Equações & Resultados \\
\hline DQOTоTAL (kg/ano) & 1 & $\begin{array}{l}\text { DQO afluente * Média de Vazão * } \\
365\end{array}$ & 228.746 \\
\hline Produção de $\mathrm{CH}_{4}$ (kg/ano) & 2 & Eq. 1 & 33.795 \\
\hline Densidade do $\mathrm{CH}_{4}\left(\mathrm{~kg} / \mathrm{Nm}^{3}\right)\left(^{*}\right)$ & 3 & - & 0,65 \\
\hline Conversão $\mathrm{P}_{\mathrm{CH} 4}\left(\mathrm{Nm}^{3} / \mathrm{ano}\right)$ & 4 & Volume $\mathrm{CH}_{4}=\mathrm{P}_{\mathrm{CH} 4} /$ Densidade & 51.992 \\
\hline $\begin{array}{l}\text { Produção útil de metano } \\
\left(\mathrm{Nm}^{3} / \mathrm{ano}\right)\left({ }^{* *}\right)\end{array}$ & 5 & $\mathrm{P}_{\mathrm{LíqCH} 4}=\mathrm{P}_{\mathrm{CH} 4}-\mathrm{P}_{\mathrm{CH} 4} * 0,34$ & 34.314 \\
\hline $\begin{array}{l}\text { Conversão do metano em biogás } \\
\left(\mathrm{Nm}^{3} / \mathrm{ano}\right)\left(^{* * *}\right)\end{array}$ & 6 & Eq. 3 & 49.020 \\
\hline $\begin{array}{l}\text { Taxa bruta de emissão de biogás } \\
\left(\mathrm{Nm}^{3} / \mathrm{kg} \text { de } \mathrm{DQO} \text { removida) }\right.\end{array}$ & 7 & - & 0,32 \\
\hline $\begin{array}{l}\text { Taxa líquida emissão de biogás } \\
\left(\mathrm{Nm}^{3} / \mathrm{kg} \text { de DQO removida) }\right.\end{array}$ & 8 & - & 0,21 \\
\hline $\begin{array}{l}\text { Vazão disponível de biogás } \\
\left(\mathrm{Nm}^{3} / \mathrm{h}\right)\end{array}$ & 9 & - & 5,60 \\
\hline
\end{tabular}

(*) Densidade do metano obtida de CETESB (2006) a $25^{\circ} \mathrm{C}$ e 1,1 atm.

${ }^{* *}$ Para o cálculo da produção útil de metano, considerou-se uma perda de $34 \%$ de metano.

$\left(^{* * *}\right)$ Para a conversão do metano em biogás, foi considerada como referência uma concentração de $70 \%$ de metano no biogás ( $\left.\mathrm{Nm}^{3} / \mathrm{ano}\right)$.

Fonte: Elaboração própria com dados de IPCC (2006) e UNFCCC (2012).

O biogás produzido por meio de digestão anaeróbia em ambiente fabril pode ser usado para a geração de energia elétrica ou energia térmica, e assim reduzir as necessidades energéticas externas, as emissões de gases do efeito estufa e a dependência de combustíveis de fontes esgotáveis (SCHOENA; BAGLEY, 2012; NWOKOLO et al., 2020).

O primeiro cenário estudado foi 0 aproveitamento do biogás para a geração de eletricidade, que teve como referência um grupo motor gerador de 7,6 kW (PECORA, 2006). Este equipamento foi selecionado por necessitar 0 consumo de biogás, considerando-se que a potência disponível do biogás obtida pela eq. 5 foi igual a 6,2 $\mathrm{kW}$.

Houve necessidade de um gasômetro para suportar possíveis variações durante a produção do 
biogás. O sistema é interligado por tubulações de inox, com válvulas e pontos de amostragem de biogás, além de um medidor de vazão, que registra a concentração de metano, a temperatura e pressão.

A Tabela 4 apresenta os equipamentos necessários para a montagem do cenário de geração própria de energia elétrica por meio do biogás na fábrica estudada. Esses equipamentos foram adaptados a partir do estudo de Pecora (2006) e de levantamentos feitos entre os fornecedores; no total, o valor do investimento inicial chegou a $R \$$ 29.738,00. O motor gerador selecionado foi dimensionado para trabalhar com $4 \mathrm{Nm}^{3} / \mathrm{h}$ de biogás, com concentração mínima de $60 \%$ de metano. A limpeza do biogás foi projetada para ser realizada por meio de filtros que acompanham o motor gerador e retiram o sulfeto de hidrogênio $\left(\mathrm{H}_{2} \mathrm{~S}\right)$.

Tabela 4 - Especificação do custo inicial de investimento para o cenário de geração própria de energia elétrica

\begin{tabular}{|c|c|c|c|c|}
\hline Materiais & Modelo & Quantidade & $\begin{array}{c}\text { Custo } \\
\text { unitário }(R \$)\end{array}$ & $\begin{array}{c}\text { Custo } \\
\text { total }(R \$)\end{array}$ \\
\hline Tubulação & Aço Inox & 8 metros & 60 & 480 \\
\hline $\begin{array}{l}\text { Válvula de } \\
\text { segurança }\end{array}$ & Aço Inox & 1 & 240 & 240 \\
\hline $\begin{array}{l}\text { Ponto de coleta } \\
\text { do biogás }\end{array}$ & Aço Inox & 2 & 150 & 300 \\
\hline $\begin{array}{l}\text { Medidor de vazão, } \\
\text { temperatura e } \\
\text { pressão }\end{array}$ & $\begin{array}{c}\text { TERMAL FT2 } \\
\text { CONTECH }\end{array}$ & 1 & 8925 & 8925 \\
\hline Válvula tipo esfera & Aço Inox & 2 & 240 & 480 \\
\hline Gasômetro & $\begin{array}{c}\text { Gasômetro PVC } \\
\left(10 \mathrm{~m}^{3}\right)\end{array}$ & 1 & 4704 & 4704 \\
\hline Motor gerador & $\begin{array}{c}\text { B4T-10000 } \\
\text { BIOFLEX/BRANCO }\end{array}$ & 1 & 14.609 & 14.609 \\
\hline Total & & - & - & 29.738 \\
\hline
\end{tabular}

Fonte: Elaboração própria com dados de Pecora (2006).

Foi considerada uma taxa de $10 \%$ do custo total do motor gerador para o seu possível recondicionamento a cada 12 meses ou após decorridas 5 mil horas de operação. Segundo Amador (2000), uma vez cumprido o número de horas de funcionamento do motor gerador, restam algumas possibilidades: substituir todo o grupo ou substituir o motor propriamente dito ou recondicionálo. O custo do recondicionamento do grupo pode ser expresso por um porcentual do custo do investimento inicial do motor gerador, variando entre 10 e $25 \%$ desse valor. O custo total de manutenção foi estimado em aproximadamente $R \$ 5315,00 /$ ano, considerando-se serviços como trocas periódicas do óleo do motor, trocas dos filtros de ar e de biogás, verificação e troca de válvulas, limpeza do cabeçote e uma retífica do motor após decorridas $5000 \mathrm{~h}$ de operação por ano.

Através da vazão de biogás igual $5,60 \mathrm{Nm}^{3} / \mathrm{h}$, determinada neste trabalho (Tabela 3 ), pode-se estimar que o motor gerador avaliado produziu cerca de $45.311 \mathrm{kWh} / \mathrm{ano}$. Considerando-se as equações 4 e 5 e a tarifa homologada para a fábrica aqui estudada igual a $R \$ 0,49336 / \mathrm{kWh}$ (ANEEL, 2021), obteve-se uma receita de $\mathrm{R} \$ 22.355,00 /$ ano. Tendo em vista o custo de manutenção referido anteriormente, estimou-se ser possível alcançar um benefício anual de $\mathrm{R} \$ 17.040,00 /$ ano com a geração própria de eletricidade na fábrica e a consequente substituição de parte do suprimento de energia 
elétrica que seria adquirido da concessionária.

$\mathrm{Em}$ virtude dos resultados encontrados foi realizada outra pesquisa de mercado em empresas especializadas para verificar outros modelos de motor gerador disponíveis, com maiores potências. Os especialistas consultados relataram que a produção de biogás da empresa em estudo é baixa para propósitos de geração de energia elétrica com um rápido retorno dos investimentos. Tal fato justifica-se pela necessidade de armazenamento do biogás em gasômetro, o que exigiria um alto investimento e uma grande área disponível para a sua implantação, pois o gás seria armazenado em pressão atmosférica.

De acordo com Dudek e colaboradores (2010), a viabilidade para aproveitamento de biogás em motores depende do volume produzido e da concentração de metano. Os autores indicam taxas viáveis situadas entre 30 e $2000 \mathrm{Nm}^{3}$ de biogás/h, com $50 \%$ de $\mathrm{CH}_{4}$. Dentre as desvantagens para a utilização do biogás quando em condições de baixa produção, pode-se apontar 0 alto custo de armazenagem, pois é um gás leve, de baixa densidade e de difícil liquefação (SALOMON; LORA, 2005).

Entretanto, o estudo realizado por Schoena e Bagley (2012), em uma indústria de lã, demostrou que, mesmo em condições de uma baixa produção relativa de biogás $\left(10 \mathrm{Nm}^{3} / \mathrm{h}\right)$, existem tecnologias que podem aproveitá-lo energeticamente. Foram realizadas simulações de geração de energia elétrica e térmica em vários equipamentos, como caldeiras, microturbina, motor a gasolina e motor striling. Os resultados destacaram a utilização do biogás na geração de vapor em caldeiras, devido à sua viabilidade econômica.

Em seguida, foi investigado o cenário de aproveitamento do biogás produzido para a geração de vapor em caldeiras. A empresa em estudo possuía duas caldeiras a GN em suas instalações, que produziam cerca de $35.239 \mathrm{~kg}$ de vapor por ano. Conforme as estimativas da equipe técnica da fábrica, essas caldeiras consumiram cerca de 2.756.938 Nm³/ano de GN para geração de vapor. O GN era fornecido pela Petrobras, com uma tarifa fixa de $R \$ 4.650,02 /$ mês e uma tarifa variável igual a $R \$$ $2,1023 / \mathrm{Nm}^{3}$ (ARSP-ES, 2021), logo, a empresa tinha um gasto anual de aproximadamente $R \$$ $5.851 .711,00$ com o suprimento de GN para geração de vapor em caldeiras.
Na Figura 3, são apresentados o reator UASB e a caldeira da fábrica em estudo. Uma das vantagens de se utilizar o biogás produzido na queima direta em caldeiras é a curta distância entre essas unidades, conforme pode ser observado na Figura 3.

Com base nas estimativas de produção de biogás no reator UASB (cerca de $49.020 \mathrm{Nm}^{3} / \mathrm{ano}$ ), foi realizada uma pesquisa de mercado para verificar as possíveis tecnologias para 0 aproveitamento térmico desse insumo em caldeiras. Foi encontrada uma empresa especializada em captação e aproveitamento do biogás em caldeiras, localizada em São Paulo, que apresentou uma proposta técnica/comercial, na qual disponibilizou os principais equipamentos a serem utilizados no cenário proposto, com um custo de implantação de $\mathrm{R} \$ 107.000,00$. Essa proposta era composta por três módulos, a saber: um (01) sistema de captação, tratamento e bombeamento de biogás para alimentação do sistema de combustão; um (01) sistema de combustão para o aproveitamento energético do biogás na caldeira e um (01) sistema de flare para a segurança do conjunto biodigestorreator-gasômetro. Todo o sistema de combustão alimentado pelo biogás atendia rigorosamente à norma ABNT no 12313 - edição 09/00, a qual estabelece que "todos os dispositivos de segurança empregados nas instalações de sistemas de combustão sejam produzidos especificamente para o uso com gás combustível e que possuam atestado de desempenho para a finalidade para a qual serão utilizados" (ABNT, 2000).

O sistema para limpeza do biogás não foi contemplado nessa proposta comercial, pois depende da análise de concentrações de $\mathrm{H}_{2} \mathrm{~S}$ para que seja determinada a melhor tecnologia de purificação, já que os investimentos oscilam de acordo com o nível de impurezas e as restrições dos equipamentos. Os limites de $\mathrm{H}_{2} \mathrm{~S}$ aceitáveis para a queima direta do biogás em caldeiras devem ser inferiores a 1000 ppm (CHAMBERS; POTTER, 2002).

Para o dimensionamento do sistema, foi considerada a concentração do metano, do oxigênio, do gás carbônico, do sulfeto de hidrogênio, a vazão disponível do biogás e o $\mathrm{PCl}$ estimado do biogás, conforme apresentados na Tabela 5.

É sabido que as caldeiras e o módulo de tratamento anaeróbio fazem parte dos processos da fábrica. Sendo assim, os custos de operação e 
manutenção desses equipamentos não foram considerados. Porém, foram contemplados os gastos com a assistência técnica anual no valor de $R \$ 1500,00$ para a verificação do sistema de geração de vapor instalado por empresas especializadas. Nessa etapa, foi necessário considerar a conversão do biogás em GN para se calcular a receita e o retorno do investimento. Para uma produção estimada de $49.020 \mathrm{Nm}^{3}$ de biogás por ano, estimase uma equivalência de $28.432 \mathrm{Nm}^{3}$ de $\mathrm{GN}$, utilizando-se o fator de conversão de $0,58 \mathrm{Nm}^{3}$ de $\mathrm{GN} / \mathrm{Nm}^{3}$ de biogás. De acordo com a eq. 6, é possível obter uma receita anual de aproximadamente $R \$ 59.772,00$. Ao descontar os custos associados com a manutenção do sistema de geração de vapor obtém-se um benefício anual igual a $R \$ 58.272,00$.
A utilização, em caldeiras, do biogás proveniente do tratamento anaeróbio de uma fábrica de cerveja no Canadá foi uma alternativa viável para aumentar a eficiência energética dessa fábrica. De acordo com Alm e colaboradores (2011), a implantação do sistema de controle automático de mistura de gás natural e biogás favoreceu uma redução no consumo de GN em cerca de 9,8\%. Em seu estudo, Jensen e Govindan (2014) demonstraram que a utilização de biogás gerado no tratamento de efluentes em uma indústria panificadora pode ser viável quando queimado em caldeiras para a geração de vapor. Entretanto, a conclusão desse estudo também mostrou que a viabilidade dos investimentos depende das políticas de incentivo estatais e dos custos inerentes à implantação do projeto.

Figura 3 - Fotografia do reator UASB e das caldeiras

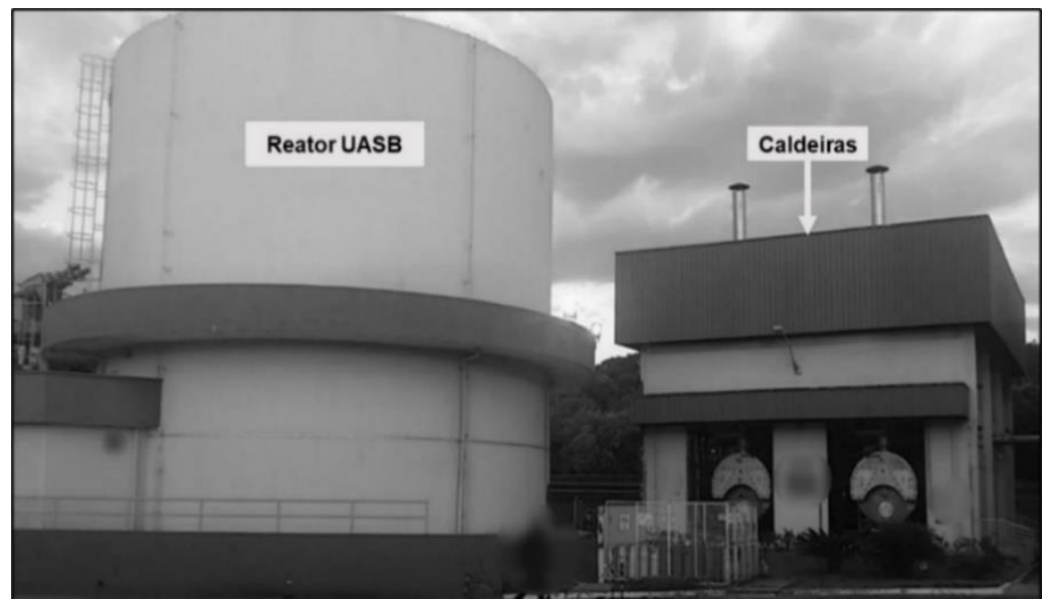

Fonte: Elaboração própria (2021).

Tabela 5 - Características do biogás gerado para dimensionamento do sistema de aproveitamento energético a partir da queima do biogás em caldeira para geração de vapor

\begin{tabular}{ll}
\hline Parâmetro & Concentração \\
\hline $\mathrm{CH}_{4}$ & $70 \%$ \\
$\mathrm{O}_{2}$ & $1,70 \%$ \\
$\mathrm{CO}_{2}$ & $40 \%$ \\
$\mathrm{H}_{2} \mathrm{~S}$ & $<1000 \mathrm{ppm}$ \\
Vazão do biogás disponível & $5,6 \mathrm{Nm}^{3} / \mathrm{h}$ \\
$\mathrm{PCl}$ biogás estimado & $5500 \mathrm{kcal} / \mathrm{Nm}^{3}$ \\
\hline
\end{tabular}

Fonte: Chambers e Potter (2002) e Felca e colaboradores (2015). 
A Tabela 6 apresenta, de forma concisa, os resultados obtidos no presente trabalho para ambos os cenários de aproveitamento energético do biogás gerado. Mostra também o tempo de retorno dos investimentos iniciais, tendo em vista a necessidade de aplicar uma TD de 3,50\% a.a. sobre os benefícios anuais obtidos. Na verdade, isso representa o valor do capital ao longo do tempo. A Tabela 6 exibe ainda os indicadores de viabilidade econômica dos cenários avaliados, sendo eles o VPL e a TIR.

O benefício anual obtido para a geração de vapor é cerca de 3,4 vezes maior que o benefício anual obtido no cenário de geração de eletricidade, o que indica uma possível vantagem competitiva daquela forma de aproveitamento do biogás em relação à geração de eletricidade. Entretanto, é válido ressaltar que o custo associado à instalação do sistema de geração de vapor a biogás é 3,6 vezes maior que o custo de montagem do cenário de geração de eletricidade. Cabe ressaltar ainda que o custo anual de manutenção do sistema de geração própria de eletricidade é cerca de 3,5 vezes maior que aquele estimado para o cenário de geração de vapor. Tal diferença impactou de forma considerável o benefício anual para o cenário de obtenção de eletricidade por meio do biogás e se apresentou como uma desvantagem quando se compara essa situação com a possibilidade da queima direta do biogás para a geração de vapor em caldeiras.

Tabela 6 - Resultados obtidos para os cenários de aproveitamento energético a partir do biogás para a fábrica de chocolates estudada

\begin{tabular}{|c|c|c|c|}
\hline Parâmetro & Unidade & $\begin{array}{l}\text { Geração própria } \\
\text { de eletricidade }\end{array}$ & $\begin{array}{l}\text { Geração de vapor } \\
\text { em caldeiras }\end{array}$ \\
\hline Custo do investimento inicial & $\mathrm{R} \$$ & 29.738 & 107.000 \\
\hline $\begin{array}{l}\text { Custo de manutenção por } \\
\text { ano de operação }\end{array}$ & $\mathrm{R} \$$ & 5315 & 1500 \\
\hline $\begin{array}{l}\text { Energia gerada a partir do } \\
\text { biogás por ano de operação }\end{array}$ & $\mathrm{kWh}$ & 45.311 & 251.335 \\
\hline Receita anual gerada & $\mathrm{R} \$$ & 22.355 & 59.772 \\
\hline Benefícios anuais $\left({ }^{* *}\right)$ & $\mathrm{R} \$$ & 17.040 & 58.272 \\
\hline Payback descontado & Meses & 34 & 35 \\
\hline VPL & $\mathrm{R} \$$ & 16.387 & 50.738 \\
\hline TIR & $\%$ & 31 & 27 \\
\hline
\end{tabular}

Observa-se na Tabela 6 que não existem diferenças significativas entre os tempos de retorno dos investimentos iniciais para ambos os cenários avaliados. Entretanto, por mais que haja paridade entre o tempo de retorno dos investimentos iniciais é preciso ponderar a viabilidade técnica das propostas avaliadas. No contexto analisado, a tomada de decisão acerca de qual cenário de recuperação energética do biogás será adotado na fábrica estudada deve levar em conta que o custo elevado de manutenção, a exigência de espaço físico para a instalação do gasômetro e a baixa vazão de biogás para o cenário de geração de eletricidade são aspectos mais relevantes que o tempo de retorno do 
investimento.

As análises do VPL e TIR (Tabela 6) indicaram que ambos os cenários apresentaram viabilidades econômicas favoráveis à sua instalação (VPL > 0; TIR > TD), o que demonstra que ambos os investimentos aqui avaliados são rentáveis para a fábrica. Por conseguinte, tanto para o cenário de eletricidade como para o cenário de vapor, os benefícios anuais obtidos são maiores que os pagamentos dos equipamentos e dos custos de manutenção (SANTOS et al., 2018).

Com base nos resultados obtidos anteriormente, é possível concluir que ambos os cenários de aproveitamento energético apresentaram viabilidade econômica favorável à sua implantação, mas a geração de vapor em caldeiras apresentou um conjunto superior de vantagens e deve ser priorizada pela fábrica avaliada. Considerando que as exigências técnicas e ambientais sejam cumpridas com rigor, a queima direta do biogás em caldeiras apresenta significativas vantagens se comparada à geração própria de eletricidade. Podem ser destacadas: a facilidade de adaptação dos sistemas de combustão de GN para biogás, a proximidade entre o reator UASB e as caldeiras e o seu baixo custo relativo de manutenção. Ademais, cabe ressaltar que a adoção do aproveitamento energético do biogás para geração de vapor agregará maior sustentabilidade ao ambiente fabril, pois contribuirá simultaneamente para substituição parcial do consumo de combustível de origem fóssil e evitará a emissão de gases do efeito estufa, como o metano e o gás carbônico.

\section{CONCLUSÃO}

Seguem as principais conclusões alcançadas ao término deste trabalho:

- Os resultados obtidos nesta pesquisa indicaram que os efluentes líquidos de uma fábrica de chocolates apresentaram uma média de DQO afluente elevada, igual a 3054 $\mathrm{mg} / \mathrm{L}$, e que o tratamento anaeróbio em reator do tipo UASB apresentou uma eficiência média de remoção de DQO igual a $83 \%$;

- Foi estimada uma produção de 49.020 $\mathrm{Nm}^{3}$ de biogás por ano e uma taxa de produção igual a $0,21 \mathrm{Nm}^{3}$ biogás por $\mathrm{kg}$ de
DQO removida, já consideradas as perdas estimadas;

- Ambos os cenários de aproveitamento energético avaliados (geração própria de eletricidade e geração de vapor em caldeiras) apresentaram viabilidades econômicas favoráveis (VPL > 0 e TIR > TD);

- A queima direta do biogás para geração de vapor em caldeiras mostrou-se preferível por agregar uma série de vantagens técnicas como: a pronta adaptação dos sistemas de combustão das caldeiras de GN para biogás, a proximidade física entre o reator UASB e as caldeiras, 0 baixo custo relativo de manutenção, além de maiores benefícios ambientais em relação à sua concorrente, tendo em vista a substituição parcial do consumo de $\mathrm{GN}$ e a mitigação das emissões de $\mathrm{CH}_{4}$ e $\mathrm{CO}_{2}$.

\section{AGRADECIMENTOS}

O presente trabalho foi realizado com apoio da Coordenação de Aperfeiçoamento de Pessoal de Nível Superior - Brasil (CAPES) - Código de Financiamento 001.

\section{REFERÊNCIAS}

AGÊNCIA NACIONAL DE ENERGIA ELÉTRICA ANEEL. Resolução Homologatória ํo 2.749, de 06 de agosto de 2020. Disponível em: <https://www.edp.com.br/CentralDocumentos/Tabela_T arifas_ES_MT_AT.pdf>. Acesso em: 12 jan. 2021.

ALCARAZ-IBARRA, S. et al. Treatment of chocolateprocessing industry wastewater in a low-temperature pilotscale UASB: Reactor performance and in-situ biogas use for bioenergy recovery. Biomass and Bioenergy, v. 142, p. 105786, 2020.2 DOI: https://doi.org/10.1016/j.biombioe.2020.105786.

ALM, P. et al. Sleeman biogas boiler system design. SURG Journal, v. 5, n. 1, p. 63-68, 2011. DOI: https://doi.org/10.21083/surg.v5i1.1199.

AMADOR, J. Análisis de los parámetros técnicos en la aplicación de los sistemas de información geográfica a la integración regional de las energías renovables en la producción descentralizada de 
electricidad. 270 f. Tese (Doutorado em Engenharia Elétrica) - Universidade Politécnica de Madrid, Madrid, Espanha, 2000.

AMERICAN PUBLIC HEALTH ASSOCIATION - APHA. Standard Methods: For the Examination of Water and Wastewater. 19. ed. Washington, DC: APHA, 1995.

ANTWI, P. et al. Estimation of biogas and methane yields in an UASB treating potato starch processing wastewater with backpropagation artificial neural network. Bioresource technology, v. 228, p. 106-115, 2017. DOI: https://doi.org/10.1016/j.biortech.2016.12.045.

AGÊNCIA DE REGULAÇÃO DE SERVIÇOS PÚBLICOS DO ESTADO DO ESPÍRITO SANTO - ARSP-ES. Tarifas de Gás Natural. 2021. Disponível em: $<$ https://www.arsp.es.gov.br/tarifas-gas-natural>. Acesso em: 01 jun. 2021.

ASSOCIAÇÃO BRASILEIRA DE NORMAS TÉCNICAS ABNT. NBR 12313: Sistema de combustão - controle e segurança para utilização de gases combustíveis em processos de baixa e alta temperatura. Rio de Janeiro, 2000.

ASTALS, S. et al. Co-digestion of pig manure and glycerine: experimental and modelling study. Journal of Environmental Management, v. 92, n. 4, p. 1091-1096, 2011. DOI: https://doi.org/10.1016/j.jenvman.2010.11.014.

AVACl, A. B. et al. Avaliação econômico-financeira da microgeração de energia elétrica proveniente de biogás da suinocultura. Revista Brasileira de Engenharia Agrícola e Ambiental, v. 17, n. 4, p. 456-462, 2013. DOI: https://doi.org/10.1590/S1415-43662013000400015.

BANCO CENTRAL DO BRASIL - BCB. Taxas de Juros Básicas-Histórico. 2021. Disponível em: <https://www.bcb.gov.br/controleinflacao/historicotaxasju ros>. Acesso em: 07 jun. 2021.

BEAL, L. J.; RAMAN, D. R. Sequential two-stage anaerobic treatment of confectionery wastewater. Journal of Agricultural Engineering Research, v. 76, n. 2, p. 211-217, 2000. DOI: https://doi.org/10.1006/jaer.2000.0555.

CAMPELLO, L. D et al. Analysis of the economic viability of the use of biogas produced in wastewater treatment plants to generate electrical energy. Environment, Development and Sustainability, v. 23, n. 2, p. 26142629, 2021. DOI: https://doi.org/10.1007/s10668-02000689-y.

CERVI, R. G.; ESPERANCINI, M. S. T.; BUENO, O. C. Viabilidade econômica da utilização do biogás produzido em granja suinícola para geração de energia elétrica. Engenharia Agrícola, v. 30, n. 5, p. 831-844, 2010. DOI: https://doi.org/10.1590/S0100-69162010000500006.

CHAMBERS, A. K.; POTTER, I. Gas utilization from sewage waste. Alberta Research Council, Canadá, p. 113, 2002. Disponível em: <http://citeseerx.ist.psu.edu/viewdoc/download?doi=10.1 .1.476.516\&rep=rep1\&type=pdf $>$. Acesso em: 07 jun. 2021.

CHEN, R. et al. Energy recovery potential of thermophilic high-solids co-digestion of coffee processing wastewater and waste activated sludge by anaerobic membrane bioreactor. Bioresource Technology, v. 274, p. 127-133, 2019. DOI: https://doi.org/10.1016/j.biortech.2018.11.080.

CHERNICHARO, C. A. L. Princípios do tratamento biológico de águas residuárias: Reatores anaeróbios. 2. ed. Departamento de Engenharia Sanitária e Ambiental - DESA/UFMG, Belo Horizonte: Editora UFMG, 2007.

CHERNICHARO, C. A. L. et al. Anaerobic sewage treatment: state of the art, constraints, and challenges.

Reviews in Environmental Science and Bio/Technology, v. 14, n. 4, p. 649-679, 2015. DOI: https://doi.org/10.1007/s11157-015-9377-3.

COMPANHIA AMBIENTAL DO ESTADO DE SÃO PAULO - CETESB. Manual do usuário do programa computacional do Biogás: Geração e Uso Energético Efluentes e Resíduos Rurais - Versão 1.0. São Paulo: Secretaria do Meio Ambiente, Ministério da Ciência e Tecnologia, 2006.

COPETTI, M. V. et al. Occurrence of ochratoxin A in cocoa by-products and determination of its reduction during chocolate manufacture. Food Chemistry, v. 136, n. $1, \quad$ p. 100-104, 2013. DOI: https://doi.org/10.1016/j.foodchem.2012.07.093.

DERELI, R. K. Modeling long-term performance of fullscale anaerobic expanded granular sludge bed reactor treating confectionery industry wastewater. Environmental Science and Pollution Research, v. 26, n. 24, p. 25037-25045, 2019. DOI: https://doi.org/10.1007/s11356-019-05739-1.

DIWANI, G. E. L. et al. Treatment of confectionery and gum factory wastewater effluent. Adsorption Science \& Technology, v. 18, n. 9, p. 813-821, 2000. DOI: https://doi.org/10.1260/0263617001493837.

DUDEK, J. et al. Landfill gas energy technologies. Kraków: Instytut Nafty i Gazu, 2010. 172 p. 
EL-FADEL, M.; MASSOUD, M. Methane emissions from wastewater management. Environmental Pollution, v. 114 , n. 2, p. 177-185, 2001. DOI: https://doi.org/10.1016/S0269-7491(00)00222-0.

EL-KALYOUBI, M. et al. Quality characteristics of chocolate-Containing some fat replacer. Annals of Agricultural Sciences, v. 56, n. 2, p. 89-96, 2011. DOI: https://doi.org/10.1016/j.aoas.2011.05.009.

ERSAHIN, M. E. et al. Anaerobic treatment of industrial effluents: an overview of applications. WastewaterTreatment and Reutilization, v. 9, n. 13, 2011.

ESPARZA-SOTO, M. et al. Treatment of a chocolate industry wastewater in a pilot-scale low-temperature UASB reactor operated at short hydraulic and sludge retention time. Water Science and Technology, v. 67, n. 6, p. 1353-1361, 2013. DOI: https://doi.org/10.2166/wst.2013.010.

FELCA, A. T. A et al. Estimativa do potencial energético de um aterro sanitário por meio de duas metodologias. In: CONGRESSO NACIONAL DE MEIO AMBIENTE, 12., 2015, Poços de Caldas. Anais [...]. Poços de Caldas: [s.n.], 2015.

GERVASONI, R.; CANTÃO, M. P. Produção de metano a partir da digestão anaeróbia: relação entre teoria $e$ prática. Revista Espaço Energia, v. 15, p. 1-10, 2011.

INTERGOVERNMENTAL PANEL ON CLIMATE CHANGE - IPCC. Wastewater Treatment and Discharge. In: IPCC Guidelines for National Greenhouse Gas Inventories. v. 5, cap. 6 . Disponível em: $<$ http://www.ipcc-

nggip.iges.or.jp/public/2006gl/index.html>. 2006. Acesso em: 12 maio 2021.

JENSEN, J. K.; GOVINDAN, K. Assessment of renewable bioenergy application: a case in the food supply chain industry. Journal of Cleaner Production, v. 66, p. 254263, 2014.

DOI: https://doi.org/10.1016/j.jclepro.2013.11.060.

LEMOS, M. V. D. Uso Eficiente de Biogás de Esgoto em Motores Geradores. 59 p. Trabalho de conclusão de curso (Graduação em Engenharia Mecânica) - Escola Politécnica da Universidade Federal do Rio de Janeiro/UFRJ, Rio de Janeiro, 2013. Disponível em: http://www.repositorio.poli.ufrj.br/monografias/monopoli1 0007949.pdf. Acesso em: 01 jun. 2021.

LIER, J. B. et al. Celebrating 40 years anaerobic sludge bed reactors for industrial wastewater treatment. Reviews in Environmental Science and
Bio/Technology, v. 14, n. 4, p. 681-702, 2015. DOI: https://doi.org/10.1007/s11157-015-9375-5.

MAINARDIS, M., BUTTAZZONI, M.; GOI, D. Up-Flow Anaerobic Sludge Blanket (UASB) Technology for Energy Recovery: A Review on State-of-the-Art and Recent Technological Advances. Bioengineering, v. 7, n. 2, p. 43, 2020.

MASSARA, T. M. et al. A mini review of the technoenvironmental sustainability of biological processes for the treatment of high organic content industrial wastewater streams. Waste and Biomass Valorization, v. $8, \quad$ n. $5, \quad$ p. $1665-1678,2017$. DOI: https://doi.org/10.1007/s12649-017-0022-y.

MOHAN, S., V. VIVEKANANDHAN; S. PRIYADHARSHINI. Performance evaluation of modified UASB Reactor for treating bakery effluent. International Journal of Applied Environmental Sciences, v. 12, n.11, p. 1883-1894, 2017.

NWOKOLO, N. et al. Waste to Energy: A Focus on the Impact of Substrate Type in Biogas Production. Processes, v. 8, n. 10, p. 1224, 2020. DOI: https://doi.org/10.3390/pr8101224.

OZGUN, H. et al. Confectionery industry: a case study on treatability-based effluent characterization and treatment system performance. Water Science and Technology, v. $66, \quad$ n. $1, \quad$ p. $15-20,2012$. DOI: https://doi.org/10.2166/wst.2012.094.

PATIL, S. A. et al. Electricity generation using chocolate industry wastewater and its treatment in activated sludge based microbial fuel cell and analysis of developed microbial community in the anode chamber. Bioresource technology, v. 100 , n. 21, p. 5132-5139, 2009. DOI: https://doi.org/10.1016/j.biortech.2009.05.041.

PECORA, V. Implementação de uma unidade demonstrativa de geração de energia elétrica a partir do biogás de tratamento do esgoto residencial da USP: Estudo de Caso. 76 f. Dissertação (Mestrado em Energia) - Universidade de São Paulo/USP, São Paulo, 2006.

PEREIRA, I. Z. et al. Vinasse biogas energy and economic analysis in the state of São Paulo, Brazil. Journal of Cleaner Production, v. 260, p. 121018, 2020. DOI: https://doi.org/10.1016/j.jclepro.2020.121018.

PILARSKA, A. A. Anaerobic Co-Digestion of Waste Wafers from Confectionery Production with Sewage Sludge. Polish Journal of Environmental Studies, v. 27, n.1, 2018. DOI: https://doi.org/10.15244/pjoes/70897. 
PILARSKA, A. A. et al. Use of confectionery waste in biogas production by the anaerobic digestion process. Molecules, v. 24, n. 1, p. 37, 2019. DOI: https://doi.org/10.3390/molecules24010037.

PIN, B. V. da R. et al. Energetic use of biogas from the anaerobic digestion of coffee wastewater in southern Minas Gerais, Brazil. Renewable Energy, v. 146, p. 20842094, 2020.

RICHTER, M.; LANNES, S. C. S. Ingredientes usados na indústria de chocolates. Revista Brasileira de Ciências Farmacêuticas, v. 43, n. 3, p. 357-369, 2007.

SALOMON, K. R.; LORA, E. E. S. Estimativa do potencial de geração de energia elétrica para diferentes fontes de biogás no Brasil. Biomassa \& Energia, v. 2, n. 1, p. 5767, 2005.

SANER, A. B.; MUNGRAY, A. K.; MISTRY, N. J. Treatment of distillery wastewater in an upflow anaerobic sludge blanket (UASB) reactor. Desalination and Water Treatment, v. 57, n. 10 , p. 4328-4344, 2016. DOI: https://doi.org/10.1080/19443994.2014.994107.

SANTOS, I. F. S. dos et al. Combined use of biogas from sanitary landfill and wastewater treatment plants for distributed energy generation in Brazil. Resources, Conservation and Recycling, v. 136, p. 376-388, 2018. DOI: https://doi.org/10.1016/j.resconrec.2018.05.011.

SCHOENA, E. J.; BAGLEY, D. M. Biogas production and feasibility of energy recovery systems for anaerobic treatment of wool-scouring effluent. Resources, Conservation and Recycling, v. 62, p. 21-30, 2012. DOI: https://doi.org/10.1016/j.resconrec.2012.02.004.

SHOW, K. Y.; LEE, D. J. Carbon credit and emission trading: Anaerobic wastewater treatment. Journal of the Chinese Institute of Chemical Engineers, v. 3, n. 6, p. 557-562, 2008.2 DOI: https://doi.org/10.1016/j.jcice.2008.05.014.

UNITED NATIONS FRAMEWORK CONVENTION ON CLIMATE CHANGE - UNFCCC. Type III, AMS III.H. Methane recovery in wastewater treatment. Version 16.0. Approved Methodologies for Small Scale CDM Project Activities. 2012. Disponível em: <http://cdm.unfccc.Int/methodologies/DB/4ND00PCGC7 WXR3LOLOJT S6SVZP4NSU>. Acesso em: 12 maio 2021.

WELLINGER, A.; LINDBERG, A. In: BIOGAS EVENT 2000: KICK-OFF FOR A FUTURE DEPLOYMENT OF BIOGAS TECHNOLOGY, 22-24, 2000, Eskilstuna, Sweden. Proceedings [...] Eskilstuna: [s.n.], 2000.

ZAJDA, M.; ALEKSANDER-KWATERCZAK, U. Wastewater Treatment Methods for Effluents from the Confectionery Industry-an Overview. Journal of Ecological Engineering, v. 2, n. 9, 2019. DOI: 10.12911/22998993/112557.

ZHANG, Q.; HU, J.; LEE, D. Biogas from anaerobic digestion processes: Research updates. Renewable Energy, v. 98, p. 108-119, 2016. DOI: https://doi.org/10.1016/j.renene.2016.02.029. 